\title{
Rancang Bangun Praktikum Instrumentasi Industri Pertanian Menggunakan Augmented Reality
}

\author{
Putu Bagus Indra Sukadiana Putra ${ }^{1}$, Ida Bagus Gede Manuaba ${ }^{2}$ Linawati $^{3}$
}

[Submission: 07-12-2020, Accepted: 21-01-2021]

\begin{abstract}
Augmented Reality technology applied in the world of education can make the learning process more effective and more efficient. This study built an augmented reality application by applying the marker based tracking method which was then applied to the industrial instrumentation practicum course at the Faculty of Agricultural Technology, Udayana University. This aims to make practicum more effective and efficient. The resulting application is then tested using 2 tests, namely usability testing using the Usability method with a Likert scale and comparison testing using the Paired Sample T-test method. Usability testing aims to determine an assessment of the usability level of the application. In this test, we get a reusability value of 73.5 from a scale of $0-100$. These results can be interpreted that this application has a good usability value. Comparative testing using the Paired Sample T-test method aims to obtain information on the extent of the comparison of the understanding of each respondent before and after the application of augmented reality in industrial instrumentation courses. In this test, the Sig. (2-tailed) of 0,000 which is still below the threshold of the Paired Sample T-test, which is 0.05. So this research concludes that there is a real difference between the results before and after the respondents used the application. This study concludes that the functionality of using this application can be considered to replace the visit of industrial instrumentation practicum courses so that the implementation of practicum becomes more effective and efficient.
\end{abstract}

Intisari-Teknologi Augmented Reality yang diterapkan dalam dunia Pendidikan dapat menciptakan proses pembelajaran menjadi lebih efektif serta lebih efisien. Penelitian ini membangun sebuah aplikasi augmented reality dengan melakukan penerapan metode marker based tracking yang kemudian diterapkan pada mata kuliah praktikum instrumentasi industri di Fakultas Teknologi Pertanian Universitas Udayana. Hal ini bertujuan agar pelaksanaan praktikum menjadi lebih efektif dan efisien. Aplikasi yang dihasilkan selanjutnya diuji menggunakan 2 pengujian yaitu pengujian usabilitas menggunakan metode Usability dengan skala Likert dan pengujian komparasi dengan penerapan metode Paired Sample T-test. Pengujian Usability bertujuan untuk mengetahui penilaian mengenai tingkat kegunaan dari aplikasi. Pada pengujian ini mendapatkan nilai usabilitas sebesar 73,5 dari skala 0-100. Hasil tersebut dapat diartikan bahwa aplikasi ini memiliki memiliki nilai usabilitas yang baik. Pengujian

\footnotetext{
${ }^{1}$ Mahasiswa Magister Teknik Elektro Bidang Studi Manajemen Sistem Informasi dan Komputer Universitas Udayana, Kampus Sudirman Denpasar Bali (telp. 0361-239599; fax: 0361-239599; email: indra.sukadianaputra@gmail.com)

${ }^{2}$ Staff Pengajar, Magister Teknik Elektro. Universitas Udayana, Kampus Sudirman Denpasar Bali (telp. 0361-239599; fax:10361-239599;email:_2bgmanuaba@unud.ac.id,

3linawati@unud.ac.id)
}

komparasi menggunakan metode Paired Sample T-test bertujuan untuk mendapatkan informasi sejauh mana perbandingan dari pemahaman setiap responden sebelum dan setelah adanya aplikasi augmented reality mata kuliah instrumentasi industri. Pada pengujian ini didapatkan nilai Sig. (2-tailed) sebesar 0,000 yang masih di bawah ambang batas dari syarat Paired Sample T-test yaitu 0,05. Sehingga penelitian ini menyimpulkan bahwa adanya perbedaan yang nyata diantara hasil sebelum dan setelah responden menggunakan aplikasi. Penelitian ini menyimpulkan bahwa secara fungsionalitas penggunaan aplikasi ini dapat dipertimbangkan untuk menggantikan kegiatan kunjungan mata kuliah praktikum instrumentasi industri agar pelaksanaan praktikum menjadi lebih efektif dan efisien.

Kata Kunci- Instrumentasi Industri, Augmented Reality, Usability, Paired Sample T-test.

\section{PENDAHULUAN}

Teknologi saat ini berkembang semakin pesat. Teknologi dapat memudahkan seseorang dalam melakukan sebuah pekerjaan. Teknologi Augmented Reality sampai saat ini masih sangat diminati. Augmented Reality juga dapat diartikan sebagai aplikasi penggabungan dunia nyata dengan dunia virtual dalam bentuk dua dimensi maupun tiga dimensi yang diproyeksikan dalam sebuah lingkungan nyata dalam waktu yang bersamaan [1]. Secara sederhana Augmented Reality bisa didefinisikan sebagai lingkungan nyata yang ditambahkan obyek virtual [2]. Perpaduan dunia virtual dan dunia nyata ini diharapkan bisa membawa sebuah proses pembelajaran yang lebih efektif dan efisien dalam dunia pendidikan [3]. Beberapa penelitian sebelumnya mengenai pemanfaatan teknologi Augmented Reality yaitu "Pemanfaatan Augmented Reality (AR) pada Media Pembelajaran Pengenalan Komponen Elektronika Berbasis Android'. Penelitian ini mengembangkan sebuah aplikasi pembelajaran pengenalan komponen elektronika secara digital kepada siswa dengan pemanfaatan teknologi Augmented Reality serta menyediakan informasi dalam bentuk digital dan multimedia. Aplikasi ini diharapkan mampu menambah minat dan keingintahuan para siswa untuk lebih mengenal komponen elektronika beserta fungsinya [4]. Penelitian selanjutnya yaitu "Rancang Bangun Augmented Reality (AR) Berbasis Android Untuk Pengembangan Media Pembelajaran Fisika". Penelitian ini mengembangkan sebuah media pembelajaran inovatif untuk meningkatkan prestasi siswa dari permasalahan mata pelajaran Fisika melalui implementasi teknologi Augmented Reality (AR) berbasis android. Pada mata pelajaran Fisika terdapat fenomena yang harus divisualisasikan sebagai upaya mewujudkan kualitas pembelajaran yang efektif [5]. 
Universitas Udayana adalah perguruan tinggi negeri yang terletak di Bali. Universitas Udayana memiliki 13 fakultas dan 112 jurusan di berbagai jenjang dan telah memanfaatkan perkembangan teknologi dalam pelayanan akademik maupun proses belajar mengajar. Dibawah Universitas Udayana terdapat salah satu fakultas yang belum optimal dalam melakukan penerapan dan pemanfaatan teknologi pada saat proses belajar dan mengajar, terutama saat melakukan kegiatan praktikum di laboratorium. Fakultas tersebut adalah Fakultas Teknologi Pertanian. Fakultas Teknologi Pertanian memiliki 4 program studi. Semua program studi tersebut mewajibkan mahasiswa untuk mengikuti mata kuliah praktikum penelitian di laboratorium yang berada di Gedung Fakultas Teknologi Pertanian Bukit Jimbaran dan di Gedung Agrokomplek Kampus Sudirman.

Mata kuliah Praktikum Instrumentasi Industri merupakan mata kuliah praktikum dasar pada program studi Teknologi Industri Pertanian (TIP) yang wajib diikuti oleh mahasiswa. Mata kuliah praktikum ini akan membagi mahasiswa menjadi beberapa kelompok dan berkunjung ke setiap laboratorium secara bergantian dengan dibimbing oleh laboran. Permasalahan yang muncul yaitu tidak adanya efisensi waktu pada saat kegiatan praktikum Instrumentasi Industri dilaksanakan. Dalam pelaksanaannya, kegiatan praktikum ini harus membagi mahasiswa menjadi 6-8 kelompok yang nantinya akan diajak berkunjung ke setiap laboratorium untuk melakukan pengenalan instrumen laboratorium.

Berdasarkan hal tersebut, diperlukan sebuah perancangan dan penerapan teknologi agar kegiatan pada praktikum Intrumentasi Industri tersebut menjadi lebih efisien. Oleh karena itu, rancang bangun teknologi Augmented Reality pada mata kuliah praktikum Instrumentasi Industri pada Program Studi Teknologi Industri Pertanian (TIP) Fakultas Teknologi Pertanian diharapkan mampu untuk dijadikan solusi pemanfaatan waktu praktikum menjadi lebih singkat dan tidak perlu lagi berkunjung ke setiap laboratorium untuk melakukan pengenalan instrumen. Perancangan ini kemudian akan dievaluasi dengan metode pengujian Usability dengan menggunakan skala Likert serta pengujian komparasi dengan menggunakan penerapan metode Paired Sample T-test untuk mengetahui efektivitas dan efisiensi mata kuliah praktikum Instrumentasi Industri setelah dilakukan penerapan teknologi Augmented Reality pada praktikum tersebut.

\section{METODE PENELITIAN}

\section{A. Alur Penelitian}

Diagram alur penelitian yang dilakukan dapat dilihat pada gambar 1 .

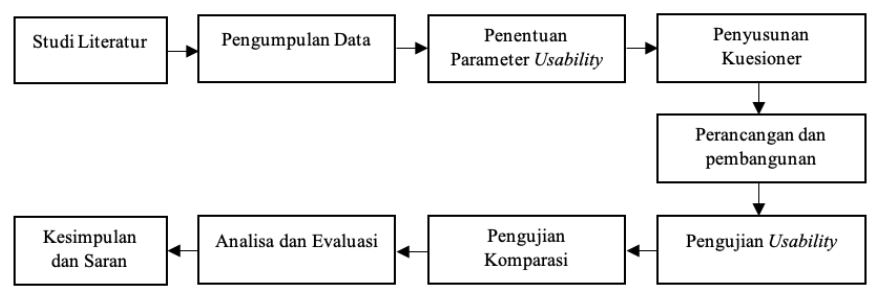

Gambar 1: Diagram Alur Penelitian

Tahapan penelitian pada gambar 1 terdiri dari:

1. Pengumpulan data ini memiliki tujuan untuk melakukan pengumpulan data yang dibutuhkan dalam perancangan dan pembangunan aplikasi.

2. Penentuan parameter usability yang bertujuan menentukan parameter usability sesuai dengan kebutuhan dari aplikasi yang dirancang.

3. Penyusunan kuesioner yang bertujuan melakukan penyusunan kuesioner sebagai alat ukur pengujian.

4. Perancangan dan pembangunan aplikasi yang bertujuan merancang dan membangun aplikasi Augmented Reality dengan melakukan penerapan metode Marker Based Tracking.

5. Pengujian Usability bertujuan untuk mengetahui tingkat usabilitas aplikasi yang telah dibangun menggunakan skala likert.

6. Pengujian komparasi bertujuan mengetahui fungsionalitas aplikasi menggunakan metode Paired Sample T-Test.

7. Analisa dan evaluasi bertujuan kesesuaian kondisi awal dengan konsep yang diinginkan.

\section{B. Gambaran Umum Sistem}

Aplikasi Augmented Reality mata kuliah praktikum Instrumentasi Industri ini sebagai upaya untuk menciptakan pelaksanaan kegiatan praktikum mata kuliah instrumentasi industri lebih efektif dan efisien.

Gambar 2 merupakan skenario penggunaan aplikasi untuk memperjelas alur dari penggunaan aplikasi augmented reality ini.

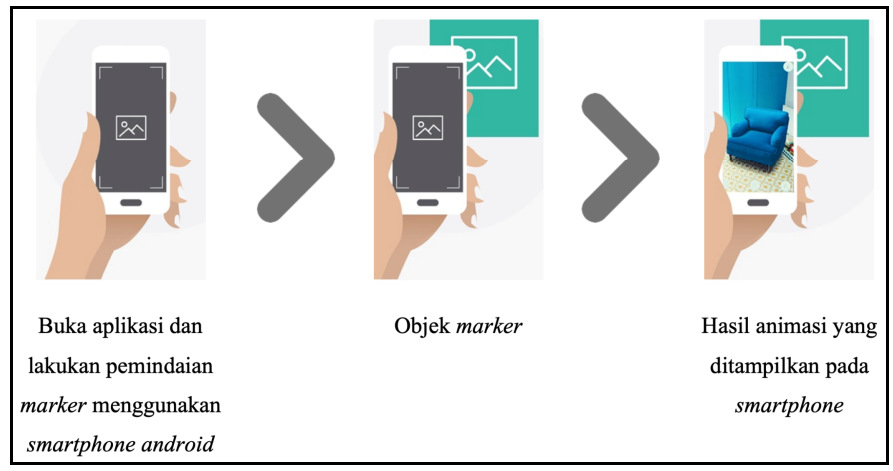

Gambar 2: Skenario Aplikasi $A R$ Instrumentasi Industri

\section{Pembangunan Objek 3D dan Marker}

Marker adalah metode pemindaian yang banyak digunakan dalam pengaplikasian Augmented Reality, hal tersebut dikarenakan marker dinilai memiliki mekanisme pengenalan yang sederhana [6]

Pembangunan Objek 3D dan Marker sesuai dengan materi praktikum Instrumentasi Pengendalian Mutu pada mata kuliah Instrumentasi Industri. Software Autodesk 3D dan Blender digunakan untuk melakukan pembangunan Objek 3D, kemudian Adobe Photoshop CC 2020 beserta software Corel Draw X7 digunakan untuk melakukan pembangunan Marker pada aplikasi. Tabel I merupakan desain objek 3D dan Marker. 
TABEL I

NAMA INSTRUMEN, OBJEK 3D, DAN MARKER YANG DigUNAKAN PADA APLIKASI

\begin{tabular}{llll}
\hline No $\quad$ Nama Instrumen & Objek 3D & Marker \\
\hline & $\mathrm{pH}$ Meter &
\end{tabular}

Atomic Absorption

2 Spectrophotometry (AAS)
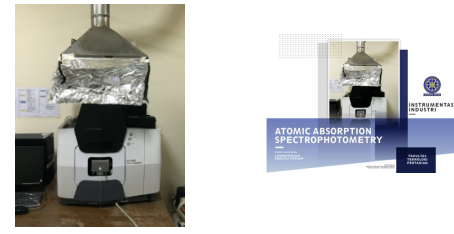

Gas

3 Chromatography

(GC)
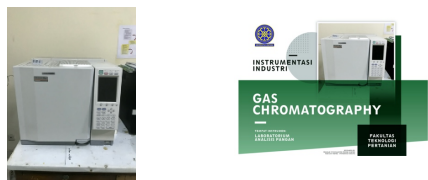

$4 \quad$ Spektrofotometer
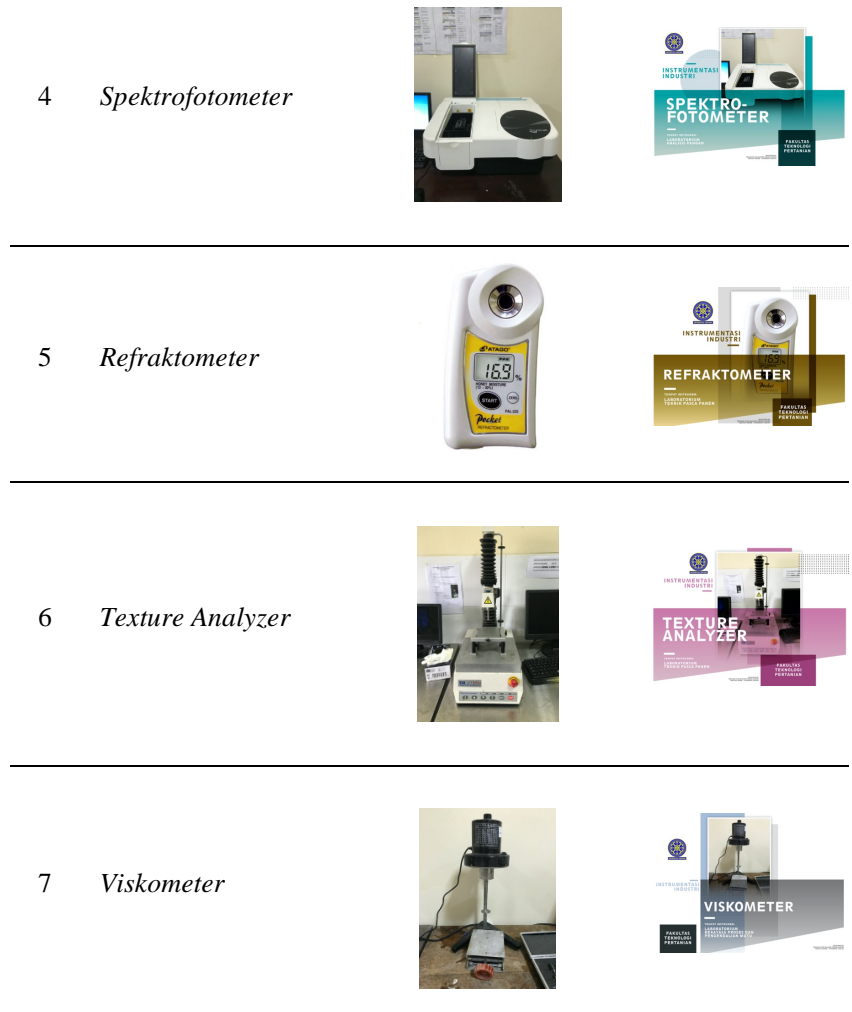

D. Pembangunan Aplikasi

Adanya integrasi antara objek 3D dan file marker pada proses pembangunan aplikasi augmented reality. Objek 3D diolah menggunakan software Unity 3D. Unity 3D merupakan game engine untuk mengolah grafik dua dimensi dan tiga dimensi yang dapat dibangun pada beberapa platform yaitu iOS, Android, Windows, MacOs, Xbox One, PS3, PS4, dan lainnya. Unity 3D menggunakan bahasa pemrograman meliputi java script, c\# script, dan boo [7].

Sedangkan untuk file marker diolah menggunakan Vuforia SDK. Vuforia adalah salah satu Software Development Kit Augmented Reality (SDK) untuk perangkat mobile yang disediakan oleh Qualcomm untuk membantu para developer membuat aplikasi Augmented Reality di smartphone (iOS, Android) [8]. Vuforia SDK menggunakan teknologi Computer Vision untuk mengenali dan melacak gambar planar (Target Image) dan objek 3D sederhana [9]. Pengerjaan pembangunan aplikasi augmented reality Instrumentasi Industri dapat dilihat pada flowchart gambar 3 .

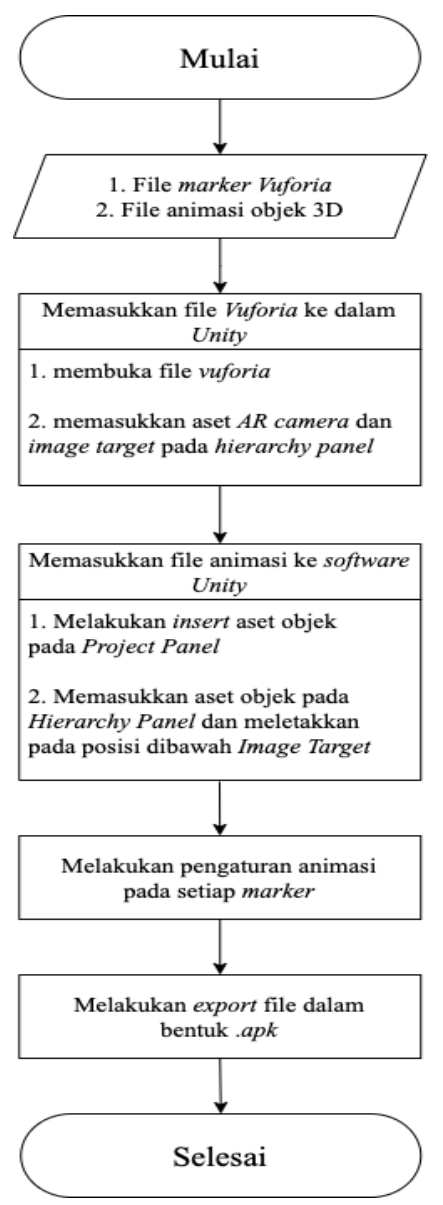

Gambar 3: Flowchart Pembangunan Aplikasi Augmented Reality Instrumentasi Industri

p-ISSN:1693 - 2951; e-ISSN: 2503-2372

Putu Bagus Indra Sukadiana Putra:Rancang Bangun Praktikum Instrumentasi ... 
Image target kemudian disesuaikan dengan objek 3D serta Reality Instrumentasi Industri. Gambar 4 merupakan proses animasi yang akan ditampilkan pada aplikasi Augmented pengaturan image target.

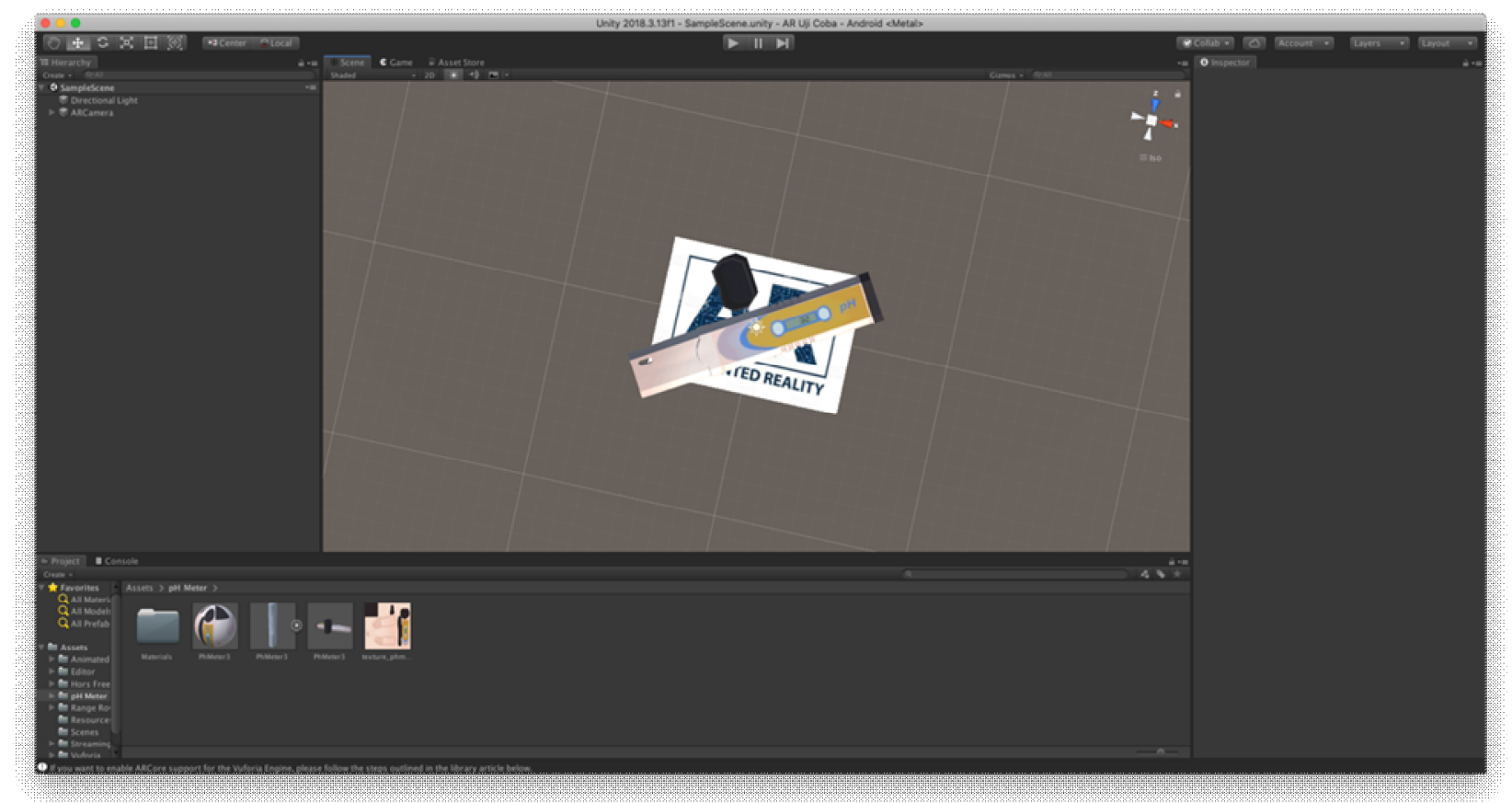

Gambar 4: Hasil dari penyesuaian image target dan objek 3D

Gambar 5 merupakan hasil dari file Apk yang sudah di ekspor dan terpasang pada android.

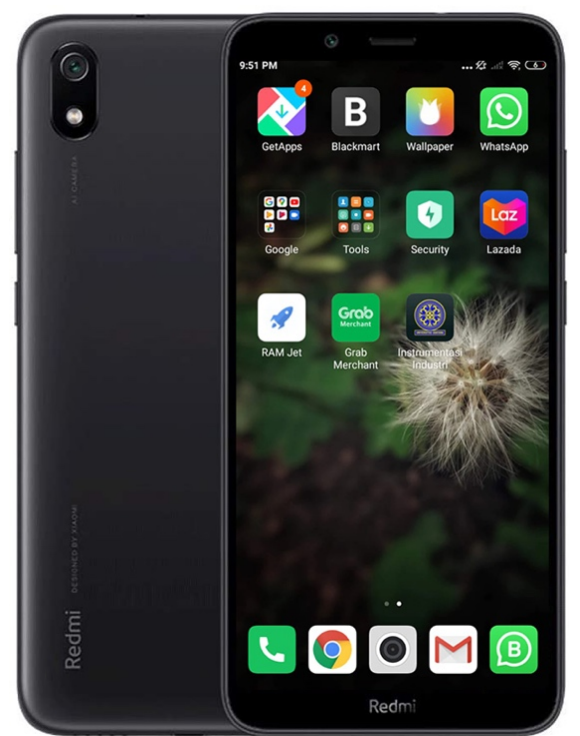

Gambar 5: Hasil dari file Apk yang sudah terinstal pada android

\section{HASIL DAN PEMBAHASAN}

\section{A. Pengujian Usability}

Usability merupakan atribut yang berfungsi untuk mengukur kemudahan penggunaan terhadap sebuah antar muka (interface) [10]. System Usability Scale merupakan pengujian usability yang efektif untuk digunakan pada berbagai jenis aplikasi [11]. Pengujian Usability ini menggunakan skala likert. Skala likert adalah skala yang digunakan untuk mengukur sikap, pendapat, dan persepsi seseorang atau kelompok terhadap suatu gejala atau fenomena [12].

Pengujian Usability dilakukan dalam bentuk kuesioner Google Form. Kuesioner tersebut berperan sebagai media untuk melakukan pengukuran pengujian. Kuesioner yang berisi 10 poin pernyataan kemudian disebarkan ke 30 responden. Terdapat 4 pilihan tanggapan pada setiap pernyataan dalam kuesioner yaitu: Sangat Tidak Setuju, Tidak Setuju, Setuju, dan Sangat Setuju. Kuesioner pengujian dapat dilihat pada tabel II.

TABEL II

KUESIONER PENGUJIAN USABILITY

\begin{tabular}{|c|c|c|c|c|c|}
\hline \multirow[b]{2}{*}{ No } & \multirow[b]{2}{*}{ Pernyataan } & \multicolumn{4}{|c|}{ Tanggapan } \\
\hline & & $\begin{array}{l}\text { Sangat } \\
\text { Tidak } \\
\text { Setuju }\end{array}$ & $\begin{array}{l}\text { Tidak } \\
\text { Setuju }\end{array}$ & Setuju & $\begin{array}{l}\text { Sangat } \\
\text { Setuju }\end{array}$ \\
\hline 1 & $\begin{array}{l}\text { Saya rasa saya akan } \\
\text { sering } \\
\text { mengggunakan } \\
\text { aplikasi ini }\end{array}$ & & & & \\
\hline 2 & $\begin{array}{l}\text { Saya rasa aplikasi } \\
\text { ini terlalu rumit }\end{array}$ & & & & \\
\hline 3 & $\begin{array}{l}\text { Saya rasa aplikasi } \\
\text { ini mudah untuk } \\
\text { digunakan }\end{array}$ & & & & \\
\hline
\end{tabular}


Majalah Ilmiah Teknologi Elektro, Vol. 20, No.1, Januari - Juni 2021

DOI: https://doi.org/10.24843/MITE.2021.v20i01.P03

\begin{tabular}{|c|c|c|c|c|c|}
\hline \multirow[b]{2}{*}{ No } & \multirow[b]{2}{*}{ Pernyataan } & \multicolumn{4}{|c|}{ Tanggapan } \\
\hline & & $\begin{array}{l}\text { Sangat } \\
\text { Tidak } \\
\text { Setuju }\end{array}$ & $\begin{array}{l}\text { Tidak } \\
\text { Setuju }\end{array}$ & Setuju & $\begin{array}{l}\text { Sangat } \\
\text { Setuju }\end{array}$ \\
\hline 4 & $\begin{array}{l}\text { Saya rasa saya } \\
\text { memerlukan } \\
\text { bantuan seseorang } \\
\text { untuk menggunakan } \\
\text { aplikasi }\end{array}$ & & & & \\
\hline 5 & $\begin{array}{l}\text { Saya rasa berbagai } \\
\text { fungsi } \\
\text { aplikasi ini telah } \\
\text { terintegrasi secara } \\
\text { baik }\end{array}$ & & & & \\
\hline 6 & $\begin{array}{l}\text { Saya rasa terdapat } \\
\text { banyak } \\
\text { inkonsistensi dalam } \\
\text { aplikasi }\end{array}$ & & & & \\
\hline 7 & $\begin{array}{l}\text { Saya rasa orang- } \\
\text { orang akan belajar } \\
\text { menggunakan } \\
\text { aplikasi ini dengan } \\
\text { cepat }\end{array}$ & & & & \\
\hline 8 & $\begin{array}{l}\text { Saya rasa aplikasi } \\
\text { ini sangat sulit } \\
\text { untuk digunakan }\end{array}$ & & & & \\
\hline 9 & $\begin{array}{l}\text { Saya merasa sangat } \\
\text { yakin dalam } \\
\text { menggunakan } \\
\text { aplikasi ini }\end{array}$ & & & & \\
\hline 10 & $\begin{array}{l}\text { Saya perlu belajar } \\
\text { banyak sebelum } \\
\text { dapat menggunakan } \\
\text { aplikasi ini }\end{array}$ & & & & \\
\hline
\end{tabular}

\begin{tabular}{ccc}
\hline No & Tanggapan & Nilai \\
\hline 1 & Sangat Tidak Setuju & 4 \\
\hline 2 & Tidak Setuju & 3 \\
\hline 3 & Setuju & 2 \\
\hline 4 & Sangat Setuju & 1 \\
\hline
\end{tabular}

Nilai tanggapan setiap responden yang telah dikonversikan sesuai dengan tabel III dan IV kemudian dijumlahkan untuk memperoleh nilai total dari setiap responden. Nilai total tersebut selanjutnya dihitung menggunakan rumus untuk memperoleh nilai usabilitasnya. Gambar 6 merupakan rumus perhitungan untuk memperoleh nilai usabilitas [13].

\section{Nilai Usabilitas $=$ Total Nilai Responden $\times 2,5$}

Gambar 6: Perhitungan Nilai Usabilitas

Dari perhitungan menggunakan rumus diatas, maka diperoleh nilai usabilitas dari setiap responden. Data rekapitulasi nilai usabilitas dari setiap responden dapat dilihat pada tabel V. Data dalam bentuk grafik dapat dilihat pada gambar 7.

TABEL V

DATA REKAPITULASI NILAI USABILITAS SETIAP RESPONDEN

\begin{tabular}{|c|c|c|c|c|c|c|c|c|c|c|c|}
\hline \multirow{2}{*}{ Responden } & \multicolumn{10}{|c|}{ Pernyataan } & \multirow{2}{*}{$\begin{array}{c}\text { Nilai } \\
\text { Usabilitas }\end{array}$} \\
\hline & 1 & 2 & 3 & 4 & 5 & 6 & 7 & 8 & 9 & 10 & \\
\hline 1 & 3 & 3 & 4 & 2 & 3 & 2 & 3 & 3 & 3 & 3 & 72,5 \\
\hline 2 & 3 & 3 & 4 & 3 & 3 & 3 & 3 & 4 & 4 & 3 & 82,5 \\
\hline 3 & 3 & 3 & 3 & 3 & 3 & 2 & 3 & 3 & 3 & 3 & 72,5 \\
\hline 4 & 3 & 3 & 3 & 2 & 3 & 2 & 3 & 2 & 3 & 2 & 65 \\
\hline 5 & 3 & 3 & 3 & 3 & 3 & 3 & 3 & 3 & 3 & 3 & 75 \\
\hline 6 & 3 & 2 & 4 & 2 & 4 & 3 & 4 & 3 & 4 & 2 & 77,5 \\
\hline 7 & 4 & 2 & 4 & 3 & 4 & 3 & 4 & 3 & 4 & 3 & 85 \\
\hline 8 & 4 & 4 & 4 & 3 & 4 & 3 & 3 & 3 & 3 & 3 & 85 \\
\hline 9 & 3 & 3 & 3 & 2 & 3 & 2 & 3 & 2 & 3 & 2 & 65 \\
\hline 10 & 3 & 3 & 3 & 3 & 3 & 3 & 3 & 3 & 3 & 2 & 72,5 \\
\hline 11 & 3 & 3 & 3 & 3 & 3 & 2 & 3 & 3 & 3 & 3 & 72,5 \\
\hline 12 & 4 & 4 & 4 & 4 & 4 & 4 & 4 & 3 & 3 & 3 & 92,5 \\
\hline 13 & 3 & 3 & 3 & 3 & 3 & 3 & 3 & 3 & 3 & 3 & 75 \\
\hline 14 & 3 & 3 & 3 & 2 & 3 & 3 & 3 & 3 & 3 & 2 & 70 \\
\hline 15 & 3 & 3 & 3 & 3 & 3 & 4 & 3 & 3 & 3 & 2 & 75 \\
\hline 16 & 3 & 3 & 3 & 2 & 3 & 3 & 2 & 3 & 3 & 2 & 67,5 \\
\hline 17 & 3 & 3 & 4 & 3 & 3 & 3 & 4 & 4 & 3 & 2 & 80 \\
\hline
\end{tabular}

Tanggapan setiap responden kemudian dihitung berdasarkan nilai yang sudah ditentukan dari setiap pernyataan yang terbagi atas pernyataan nomor urut ganjil dan nomor urut genap dengan rincian pada tabel III dan IV.

TABEL III

Nilai Dari TANGgapan PERNYATAAN NOMOR URUT GANJIL

\begin{tabular}{ccc}
\hline No & Tanggapan & Nilai \\
\hline 1 & Sangat Tidak Setuju & 1 \\
\hline 2 & Tidak Setuju & 2 \\
\hline 3 & Setuju & 3 \\
\hline 4 & Sangat Setuju & 4 \\
\hline
\end{tabular}

TABEL IV

NiLAi DARI TANGGAPAN PERNYATAAN NOMOR URUT GENAP

Putu Bagus Indra Sukadiana Putra:Rancang Bangun Praktikum Instrumentasi ... p p-ISSN:1693 - 2951; e-ISSN: 2503-2372 


\begin{tabular}{cccccccccccc}
\hline \multirow{2}{*}{ Responden } & \multicolumn{10}{c}{ Pernyataan } & $\begin{array}{c}\text { Nilai } \\
\text { Usabilitas }\end{array}$ \\
\cline { 2 - 8 } & 1 & 2 & 3 & 4 & 5 & 6 & 7 & 8 & 9 & 10 & \\
\hline 18 & 3 & 3 & 3 & 2 & 3 & 2 & 3 & 3 & 3 & 2 & 67,5 \\
\hline 19 & 3 & 3 & 3 & 3 & 3 & 3 & 3 & 3 & 3 & 1 & 70 \\
\hline 20 & 3 & 3 & 3 & 2 & 3 & 3 & 4 & 3 & 3 & 2 & 72,5 \\
\hline 21 & 4 & 3 & 3 & 1 & 4 & 3 & 4 & 4 & 4 & 1 & 77,5 \\
\hline 22 & 4 & 3 & 3 & 3 & 3 & 3 & 3 & 4 & 3 & 3 & 80 \\
\hline 23 & 3 & 3 & 3 & 2 & 3 & 2 & 3 & 3 & 3 & 2 & 67,5 \\
\hline 24 & 2 & 4 & 4 & 3 & 3 & 3 & 4 & 3 & 3 & 3 & 80 \\
\hline
\end{tabular}

\begin{tabular}{|c|c|c|c|c|c|c|c|c|c|c|c|}
\hline \multirow{2}{*}{ Responden } & \multicolumn{10}{|c|}{ Pernyataan } & \multirow{2}{*}{$\begin{array}{c}\text { Nilai } \\
\text { Usabilitas }\end{array}$} \\
\hline & 1 & 2 & 3 & 4 & 5 & 6 & 7 & 8 & 9 & 10 & \\
\hline 25 & 3 & 3 & 3 & 3 & 3 & 3 & 3 & 3 & 3 & 2 & 72,5 \\
\hline 26 & 3 & 2 & 3 & 1 & 3 & 3 & 3 & 3 & 3 & 1 & 62,5 \\
\hline 27 & 2 & 3 & 3 & 2 & 3 & 3 & 3 & 3 & 2 & 2 & 65 \\
\hline 28 & 3 & 3 & 3 & 2 & 3 & 3 & 3 & 3 & 3 & 2 & 70 \\
\hline 29 & 4 & 3 & 4 & 2 & 3 & 3 & 3 & 3 & 3 & 2 & 75 \\
\hline \multirow[t]{2}{*}{30} & 3 & 2 & 3 & 2 & 2 & 3 & 2 & 3 & 2 & 2 & 60 \\
\hline & \multicolumn{10}{|c|}{ Jumlah Nilai Usabilitas } & 2.205 \\
\hline
\end{tabular}

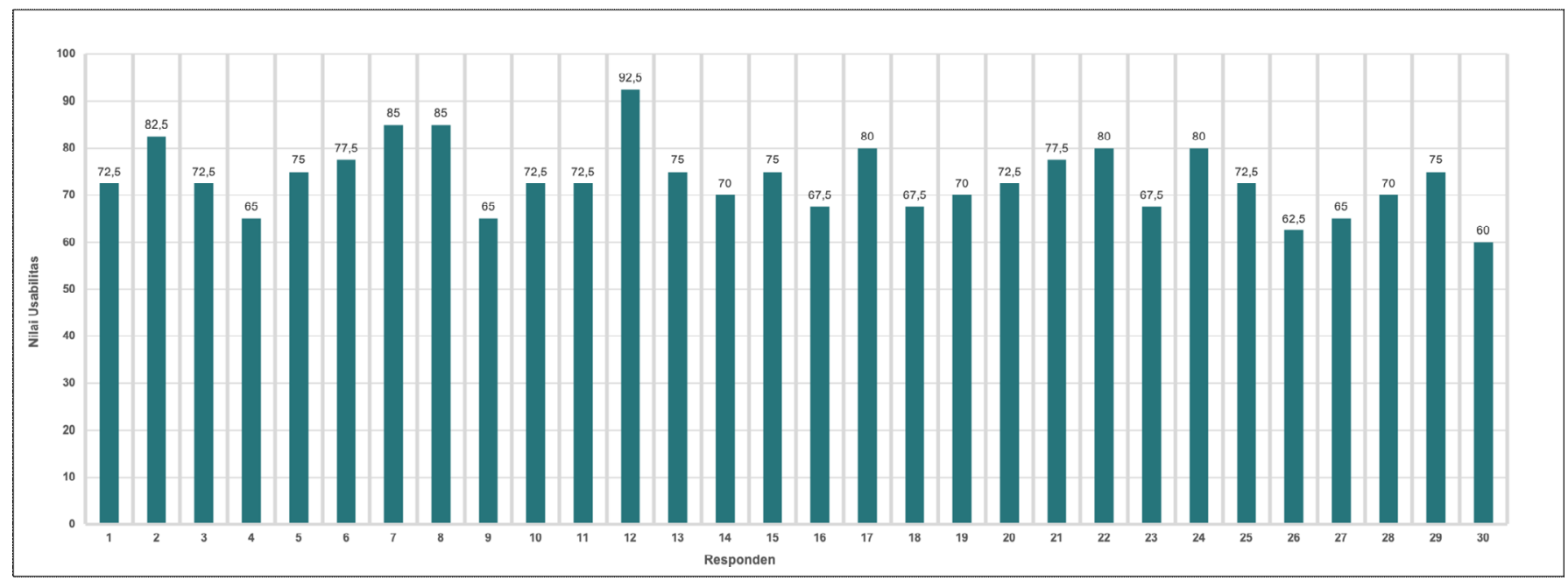

Gambar 7: Grafik Hasil Perhitungan Nilai Usabilitas Setiap Responden

Nilai usabilitas setiap responden kemudian dijumlahkan dan memperoleh nilai 2.205 sesuai dengan jumlah yang tertera pada tabel V. Untuk memperoleh nilai rata-rata dari total nilai usabilitas, maka dilakukan perhitungan dengan rumus pada gambar 8 [14][15].

$$
\bar{X}=\frac{\sum X}{N}
$$

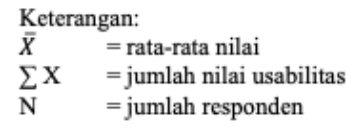

Gambar 8: Rumus Rata-Rata Nilai Usabilitas

Dari perhitungan diatas, maka diperoleh nilai rata-rata sebesar 73,5. Nilai usabilitas dari hasil pengujian Usability dikategorikan sesuai dengan rentang nilai yang dapat dilihat pada tabel VI.
TABEL VI

Rentang Nilai PENGujian USABILITY

\begin{tabular}{ccc}
\hline No & Nilai & Keterangan \\
\hline 1 & $0-25$ & Sangat Buruk \\
\hline 2 & $26-50$ & Buruk \\
\hline 3 & $51-75$ & Baik \\
\hline 4 & $76-100$ & Sangat Baik \\
\hline
\end{tabular}

Dari tabel VI dapat dilihat bahwa nilai 73,5 dari hasil pengujian Usability kepada 30 responden berada pada rentang 51-75 dengan penilaian dalam kategori baik. Hasil tersebut dapat diartikan bahwa aplikasi ini memiliki memiliki nilai usabilitas yang baik.

\section{B. Pengujian Komparasi}

Pengujian komparasi menggunakan metode Paired Sample T-test (Pre-test dan Post-test) dengan menggunakan kuesioner Google Form sebagai media alat ukur pengujian. Pengujian ini dilakukan untuk mendapatkan informasi sejauh mana perbandingan dari pemahaman setiap responden sebelum dan setelah adanya aplikasi augmented reality mata kuliah instrumentasi industri [16]. 
Data yang telah diperoleh melalui kuesioner pre-test dan post-test yang disebarkan kepada 30 responden kemudian diolah dengan menggunakan software SPSS. SPSS (Statistical Package for the Social Sciences) yaitu software khusus untuk melakukan pengolahan data statistik yang paling banyak digunakan di seluruh dunia. SPSS dipakai dalam berbagai riset

pasar, pengendalian dan perbaikan mutu (quality improvement), serta riset-riset sains [17].

Data yang telah diolah akan mendapatkan sebuah hasil perhitungan. Hasil perhitungan pada software SPSS dapat dilihat pada gambar 9 .

\begin{tabular}{|c|c|c|c|c|c|c|c|c|c|}
\hline \multicolumn{10}{|c|}{ Paired Samples Test } \\
\hline \multicolumn{10}{|c|}{ Paired Differences } \\
\hline & & \multirow[b]{2}{*}{ Mean } & \multirow{2}{*}{$\begin{array}{c}\text { Std. } \\
\text { Deviation }\end{array}$} & \multirow{2}{*}{$\begin{array}{l}\text { Std. Error } \\
\text { Mean }\end{array}$} & \multicolumn{2}{|c|}{$\begin{array}{l}95 \% \text { Confidence Interval of } \\
\text { the Difference }\end{array}$} & \multirow[b]{2}{*}{$\mathrm{t}$} & \multirow[b]{2}{*}{$\mathrm{df}$} & \multirow{2}{*}{$\begin{array}{l}\text { Sig. (2- } \\
\text { tailed) }\end{array}$} \\
\hline & & & & & Lower & Upper & & & \\
\hline Pair 1 & PreTest - PostTest & -1.767 & 1.942 & .355 & -2.492 & -1.042 & -4.983 & 29 & .000 \\
\hline
\end{tabular}

Gambar 9: Hasil Perhitungan Software SPSS

Acuan yang digunakan pada hasil perhitungan Software SPSS pada gambar 8, terletak pada kolom Sig. (2-tailed) yang meperoleh nilai 0,000. Dari hasil perhitungan tersebut, Sig. (2tailed) memperoleh nilai 0,000 dan masih di bawah ambang batas dari syarat Paired Sample T-test yaitu 0,05 [18][19][20].

Sehingga penelitian ini menyimpulkan bahwa adanya perbedaan yang nyata diantara hasil sebelum dan setelah responden menggunakan aplikasi.

\section{KESIMPULAN}

Berdasarkan penelitian, perancangan dan pembangunan aplikasi, implementasi, dan pengujian yang dilakukan, maka didapatkan kesimpulan berikut:

1. Pengujian usability pada penilaian responden mengenai tingkat usabilitas aplikasi Augmented Reality mata kuliah Instrumentasi Industri ini mendapatkan nilai usabilitas sebesar 73,5 dari rentang nilai 0-100. Hasil tersebut dapat diartikan bahwa aplikasi ini memiliki memiliki nilai usabilitas yang baik.

2. Hasil pada pengujian komparasi dengan penerapan metode Paired Sample T-test mendapatkan nilai Sig. (2-tailed) sebesar 0,000 yang masih di bawah ambang batas dari syarat Paired Sample T-test yaitu 0,05. Sehingga dapat memperoleh kesimpulan bahwa adanya perbedaan yang nyata diantara hasil sebelum dan setelah responden menggunakan aplikasi.

3. Penelitian ini menghasilkan sebuah aplikasi Augmented Reality Mata Kuliah Instrumentasi Industri yang secara fungsionalitas penggunaan aplikasi dapat dipertimbangkan untuk menggantikan kegiatan kunjungan mata kuliah praktikum instrumentasi industri agar pelaksanaan praktikum menjadi lebih efektif dan efisien.

\section{REFERENSI}

[1] L. Hakim, "Pengembangan Media Pembelajaran Pai Berbasis Augmented Reality," Lentera Pendidik. J. Ilmu Tarb. dan Kegur., vol. 21, no. 1, pp. 59-72, 2018, doi: 10.24252/lp.2018v21n1i6.

[2] P. A. T. R. Karda, I. M. A. Suyadnya, and D. C. Khrisne, "Rancang Bangun Aplikasi Augmented Reality Sebagai Media Promosi Model Tatanan Rambut Pada Barbershop Berbasis Android,"
SINTECH (Science Inf. Technol. J., vol. 1, no. 1, pp. 16-24, 2018, doi: 10.31598/sintechjournal.v1i1.226.

[3] L. Kamelia, "Perkembangan Teknologi Augmented Reality Sebagai Media Pembelajaran Interaktif Pada Mata Kuliah Kimia Dasar," Noviembre 2018, vol. IX, no. 1, p. 1, 2019, [Online]. Available: https://www.gob.mx/semar/que-hacemos.

[4] A. Harahap, A. Sucipto, and J. Jupriyadi, "Pemanfaatan Augmented Reality (Ar) Pada Media Pembelajaran Pengenalan Komponen Elektronika Berbasis Android," J. Ilm. Infrastruktur ..., no. 1, pp. 20-25, 2020, [Online]. Available: http://jim.teknokrat.ac.id/index.php/teknologiinformasi/article/view/ 266.

[5] A. Mahpudin and E. F. W. Puadi, "Rancang Bangun Augmented Reality (Ar) Berbasis Android Untuk Pengembangan Media Pembelajaran Fisika," pp. 550-560, 2018, [Online]. Available: https://jurnal.unimus.ac.id/index.php/psn12012010/article/view/425 5.

[6] D. S. Utomo, I. Arwani, and W. S. Wardhono, "Implementasi Mobile Augmented Reality Pada Aplikasi Pemilihan Sarana Dan Prasarana Laboratorium Sekolah Menengah Atas," J. Pengemb. Teknol. Inf. dan Ilmu Komput., vol. 1, no. 3, pp. 224-235, 2017.

[7] I. F. Noor, H. Tolle, and W. S. Wardhono, "Rancang Bangun Aplikasi Augmented Reality Pemilihan Sepatu Berdasarkan Ukuran Kaki Pengguna," J. Pengemb. Teknol. Inf. dan Ilmu Komput. Univ. Brawijaya, vol. 2, no. 4, pp. 1675-1682, 2018.

[8] S. P. Bowers, "Predicting success in early childhood teacher education programs," J. Early Child. Teach. Educ., vol. 19, no. 3, pp. 227-233, 2018, doi: 10.1080/0163638980190306.

[9] M. Muntahanah, R. Toyib, and M. Ansyori, "Penerapan Teknologi Augmented Reality Pada Katalog Rumah Berbasis Android (Studi Kasus Pt. Jashando Han Saputra)," Pseudocode, vol. 4, no. 1, pp. 81-89, 2017, doi: 10.33369/pseudocode.4.1.81-89.

[10] I. G. N. A. Pradhana, I. A. . Giriantari, and M. Sudarma, "Analisis dan Perancangan Sistem Pengelola Data Menuju Implementasi Data Warehouse Untuk Mendukung Administrasi E-Procurement," Maj. Ilm. Teknol. Elektro, vol. 17, no. 2, p. 245, 2018, doi: 10.24843/mite.2018.v17i02.p12.

[11] R. L. Rahardian, L. Linawati, and M. Sudarma, "Implementasi Layanan Cloud Computing Software As a Service Pada Usaha Mikro Kecil dan Menengah,” Maj. Ilm. Teknol. Elektro, vol. 17, no. 3, p. 365, 2018, doi: 10.24843/mite.2018.v17i03.p10.

[12] S. L. Rahayu, Kusrini, and H. Al Fatta, "Rancang Bangun Augmented Reality Pada Data Menu Restoran," Eksplora Inform., vol. 6, no. 1, pp. 22-32, 2016, [Online]. Available: https://eksplora.stikom-

bali.ac.id/index.php/eksplora/article/view/101/84.

[13] F. A. Pratama, R. Magdalena, and S. Ratanadewi, "Pengujian Usability Pada Sistem Informasi Inventori dan Pemesanan PT Dirgaraya Harsa," no. 1, pp. 45-52, 2019.

[14] R. Adha, "Evaluasi Usability Sistem Ujian Online Penerimaan Mahasiswa Baru Institut Teknologi dan Bisnis Bank Rakyat

Putu Bagus Indra Sukadiana Putra:Rancang Bangun Praktikum Instrumentasi ... p p-ISSN:1693 - 2951; e-ISSN: 2503-2372 
Indonesia ( BRI Institute ) Online Usability Evaluation System Exam Admission of New Technology Institute Students and Bank Rakyat Indonesia Busines," BRITech (JurnalIlmiah Ilmu Komputer, Sains Teknol. Ter., vol. 1, no. 1, pp. 48-56, 2019.

[15] D. Setiawan and S. L. Wicaksono, "Evaluasi Usability Google Classroom Menggunakan System Usability Scale," Walisongo J. Inf. Technol., vol. 2, no. 1, p. 71, 2020, doi: 10.21580/wjit.2020.2.1.5792.

[16] F. Saputra, "Perancangan Media Edukasi Kesehatan Gigi Dan Mulut Dengan Penerapan Teknologi Augmented Reality Pada Sistem Berbasis Android," 2017.

[17] S. Zein, L. Yasyifa, R. Ghozi, E. Harahap, F. Badruzzaman, and D. Darmawan, "Pengolahan dan Analisis Data Kuantitatif Menggunakan Aplikasi SPSS," J. Teknol. Pendidik. dan Pembelajaran, vol. 4, no. 1, pp. 1-7, 2019.

[18] A. A. Anggraini, T. Informatika, P. C. Riau, T. Informatika, and P. C. Riau, "Aplikasi Pembelajaran Iqra Berbasis Android Menggunakan Speech Recognition,” vol. 10, no. 2, pp. 84-89, 2020.

[19] Istiqamah, "Pembelajaran Menulis Karangan Deskripsi Dengan Model Kooperatif Tipe Stad," J. Chem. Inf. Model., vol. 53, no. 9, pp. 1689-1699, 2019.

[20] C. Montolalu and Y. Langi, "Pengaruh Pelatihan Dasar Komputer dan Teknologi Informasi bagi Guru-Guru dengan Uji-T Berpasangan (Paired Sample T-Test)," d'CARTESIAN, vol. 7, no. 1, p. 44, 2018, doi: 10.35799/dc.7.1.2018.20113. 